\title{
Does Job-Related Training Performance Decline With Age?
}

\author{
Jean E. Kubeck, Norma D. Delp, Tammy K. Haslett, and Michael A. McDaniel \\ University of Akron
}

\begin{abstract}
This meta-analytic review presents the findings of a project investigating the relationship between age and job-related training outcomes. The analysis is based on 83 effect sizes derived from 6,610 individuals. Results showed poorer training performance for older adults. In general, older adults, relative to younger adults, showed less mastery of training material $(r=-.26)$, completed the final training task more slowly $(r=.28)$, and took longer to complete the training program $(r=.42)$. Field samples generally showed smaller age effects than laboratory samples. Estimated training performance for average individuals at various ages is provided.
\end{abstract}

Training is a planned effort by an organization to facilitate the learning of job-related behavior (Wexley, 1984). Although some researchers have focused their efforts on training the middle-aged and older worker (e.g., E. Belbin \& Belbin, 1972; McFarland, 1953; Murrell, 1962; H. L. Sterns \& Doverspike, 1989; Szafran, 1966; Welford, 1958), there exists no comprehensive review of the relationship between age and training performance. Yet, as the working population ages, the issue of training older workers becomes increasingly important. The purpose of the present research was to integrate the results of extant studies that investigated age and job-related training. Specifically, in the present study we assessed the age and training performance relationship by summarizing studies that trained adults on skills necessary for successful job performance.

Work behaviors necessary for successful training performance require a broad range of motor and cognitive skills. Cognitive researchers have traditionally approached the question of age relationships to these variables by attempting to understand age-related changes in underlying cognitive processes and structures (Park, 1992; Salthouse, 1991). Major theoretical explanations for age-related declines include (a) general slowing (Cerella, 1990; Salthouse, 1985), (b) reduced inhibition-attention models (Hasher \& Zacks, 1988; McDowd \& Birren, 1990), and (c) limitations in working memory (Craik \& McDowd, 1987; Hasher \& Zacks, 1979).

The general slowing perspective suggests that observed age deficits are spread throughout the information-processing system, resulting in age-related declines in perceptual-motor and higher cognitive tasks (Cerella, 1990; Salthouse, 1985). Reliable age decrements have been found for divided attention, sus-

Jean E. Kubeck, Norma D. Delp, Tammy K. Haslett, and Michael A. McDaniel, Department of Psychology, University of Akron.

Previous versions of this article were presented at the ninth annual meeting of the Society for Industrial and Organizational Psychology April 1994, Nashville, Tennessee, and the 47th annual meeting of the Gerontological Society of America November 1994, Atlanta, Georgia. This article has benefited from the guidance of Dennis Doverspike, Martin D. Murphy, and Harvey Sterns.

Correspondence concerning this article should be addressed to Jean E. Kubeck or Michael A. McDaniel, Department of Psychology, University of Akron, Akron, Ohio 44325-4301. tained attention, and selective attention tasks. Attentional models have provided various explanations for these findings, including reduced inhibition of task-unrelated behaviors (McDowd \& Birren, 1990). Craik and McDowd (1987) suggested that because older adults have a smaller pool of processing resources, they are differentially penalized on tasks that require more resources or self-initiated processing. Similarly, age-related reduction in allocation of processing resources has a significant impact when there is a demand for effortful as opposed to automatic processing (Hasher \& Zacks, 1979), thus reducing performance on tasks involving working memory. $\mathrm{Re}$ gardless of the explanation, there is consensus that many cognitive abilities decline with age.

Of interest, however, is the discrepancy between older adults' performance on cognitive tasks in the laboratory and everyday behaviors such as job performance and other work-related variables (Salthouse, 1990). Several studies have examined the relationship between age and other job-related variables (e.g., Giniger, Dispenzieri, \& Eisenberg, 1983; McEvoy \& Cascio, 1989; Rhodes, 1983; Waldman \& Avolio, 1986). These studies have failed to confirm age-related performance or productivity declines in older workers. For instance, age is largely unrelated to job performance (Avolio, Waldman, \& McDaniel, 1990; McEvoy \& Cascio, 1989; Rhodes, 1983; Waldman and Avolio, 1986). Murphy (1989) examined the relationship of cognitive abilities to job performance variables. He proposed that job performance can be understood in terms of maintenance and transition periods over time. For instance, cognitive abilities may be highly predictive of performance in transition periods when workers must learn new skills or information but less predictive in periods of maintenance or job stability.

The major theoretical perspectives discussed above can be applied to Murphy's (1989) model (e.g., Park, 1992). For instance, the general slowing model suggests that older adults will be slower in acquiring new skills. The working memory perspective predicts that older adults will have difficulty learning new information when effortful processing is required. Similarly, attentional-inhibition models suggest that older adults will be differentially penalized with more complex material. In contrast, older adults will exhibit stable job performance in periods of maintenance (or in jobs for which only maintenance-type performance is necessary) in which the worker relies on behav- 
iors already acquired. Another way that older workers maintain competence is through the development of compensatory mechanisms and expertise (Charness \& Bosman, 1990; Salthouse, 1990).

Our literature search substantiates the findings of B. D. Smith (1990) that indicated few studies have been conducted that assess age differences in job training outcomes. Furthermore, the extant studies are often methodologically or conceptually limited for various reasons. The dominance of decrement models (i.e., general slowing, working memory, attentional-inhibition perspectives) for both cognitive and motor abilities has resulted in a decreased interest in training older adults (H. L. Sterns, 1986; H. L. Sterns \& Alexander, 1987). The generality of slowing with age, for example, suggests that older adults' reduced information-processing speed results in performance decrements across tasks (Salthouse, 1985). Such slowing effects perpetuate negative age-related stereotypes that may result in differential access to training programs. In the workplace, older adults are said to avoid retraining because they fear competition, doubt their abilities, and question the benefits of such training (H. L. Sterns, 1986). In addition, employers often deprive older workers of training opportunities (Rosen \& Jerdee, 1976).

\section{The Present Study}

The goal of this study was to assess the degree of relationship between age and training outcomes by cumulating the existing literature. We examined studies that trained employees, job applicants, and trainees in various occupational fields, as well as laboratory studies in which the training content was judged to be relevant to the world of work. Training tasks included job skills training, computer skills training, and laboratory simulations of work tasks such as map reading. Analyses are presented separately by study characteristics (i.e., type of training, type of training outcome measure, type of sample) and also by type of training content nested within training outcome measure.

\section{Method}

All effect sizes fell into one of three categories. The first category consisted of correlations between a continuous age variable and training performance. The second category consisted of correlations between a continuous age variable that had been dichotomized by the primary study's authors and training performance. The effect sizes in the first two categories were combined into one data set and analyzed as correlation coefficients. The third category consisted of training performance comparisons between groups of different ages. For example, the training performance of a group of participants 20-22 years old was compared with the training performance of a group of participants 57-86 years old (i.e., Hoyer, Hoyer, Treat, \& Baltes, 1978/1979). These effect sizes were analyzed as standardized mean differences $(d)$.

We would have preferred to treat the extreme group data as correlations and combine these data with the data from the correlational designs. This was our preference because the study design (extreme group vs. correlational data) was not a topic of interest for us and thus was a source of artifactual variance across studies. In addition, by pooling the data across the study designs, we would have a larger set of data to evaluate substantive moderator hypotheses (e.g., does the age-performance correlation vary by content of training?). Unfortunately, we did not find an acceptable way of pooling data across these designs. Among other challenges, we had no ready way of using the extreme group data to estimate what the correlation between age and performance would have been if we had continuous age data.

\section{Meta-Analysis as a Method of Research Cumulation}

The Hunter-Schmidt (1990) psychometric meta-analysis method used in this study is based on the hypothesis that much of the variation in results across studies may be due to statistical and methodological artifacts rather than to substantive differences in underlying population relationships. Some of these artifacts also reduce the effect sizes (i.e., correlation coefficients, standardized mean differences) below their true, or population, values. The method determines the variance attributable to artifacts (e.g., sampling error) and subtracts that amount from the total amount of variation. This results in an estimate of the true variation across studies and of the true average effect size (Hunter \& Schmidt, 1990).

For the correlation coefficients, the meta-analysis used sampling error corrections and training performance unreliability corrections (Hunter \& Schmidt, 1990). The reliability of the training performance score data (i.e., training mastery measures) was set at .80 (Pearlman, 1979). No reliability data were available for the time criterion measures (i.e., time to complete final task, time to complete training); perfect reliability was assumed. This causes our effect sizes between age and time criteria to be underestimates of their population values. The correlations from dichotomous age data are underestimates of the population age and performance correlations because of the range restriction on age. A base rate correction was applied to these correlations (Hunter \& Schmidt, 1990, p. 274). The mean observed correlation was used in the sampling error variance formula (Hunter \& Schmidt, 1990, pp. 208 210; Law, Schmidt, \& Hunter, 1994a, 1994b; F. L. Schmidt et al., 1993). The computer program used for the analysis is described in McDaniel (1986). Additional detail on the program is presented in Appendix B of McDaniel, Schmidt, and Hunter (1988).

The mean population distribution estimate is offered as the true correlation between age and training performance in work settings. The mean of the population distribution has been corrected for unreliability in the training performance criterion and for range restriction because of dichotomized age variables. The variance of the population distribution has been corrected for sampling error and differences across studies in the range restriction of age. The corrections for range restriction in age were limited to those coefficients from samples in which the study's primary authors had dichotomized a continuous age variable. For the meta-analysis of the standardized mean difference effect sizes $(d)$, the effect sizes were corrected for sampling error and unreliability in the criterion. The criterion reliability data and meta-analysis software used were the same as those used for the meta-analysis of the correlation coefficient.

The population $d$ effect sizes are offered as the best estimate of the true training performance difference across extreme age groups. The mean of the population distribution is corrected for unreliability in the training performance criterion. The variance of the population distribution has been corrected for sampling error. One source of variance in our population distribution, which is actually artifactual, is the different manner in which the age groups were formed among studies. To the extent that age is related to training performance, the more extreme age contrasts will yield larger effect sizes on average. For example, a study contrasting 18-year-olds with 80 -year-olds should yield a larger effect size than a study contrasting 30 -year-olds with 40 -year-olds. We could not correct for this artifactual source of variance. Thus, our estimates of the population variance overestimate the true population variance.

\section{Literature Search}

An extensive search of various computer databases and periodicals was conducted. The following databases were searched: Psychological 
Abstracts (1969-1983), Dissertation Abstracts (1985-1994), Social Science Citation Index (1972-1995); PsycLIT (1983-1995), ABI/ INFO (1971-1994), and ERIC (1982-1994). See Appendix A for a detailed list of the key search words. The manual search involved an article-by-article search of all volumes of: Aging and Work, Training and Development Journal, Training, Journal of the American Society of Training Directors, Psychology and Aging, Experimental Aging Research. Industrial Gerontology, Journal of Applied Psychology, and Journals of Gerontology. Similarly, reference lists of all materials obtained were scanned for relevant studies.

As expected, a relatively small number of studies concerning age and job-related training performance were found. The present study includes 32 studies with 83 effect sizes. No large-scale meta-analytic studies or review articles were found that addressed the age-and-trainingperformance relationship.

\section{Decision Rules}

In searching for relevant studies, certain criteria were used. First, because few studies were found that assessed training mastery of younger and older employees, we decided to include training on laboratory tasks similar to work tasks. Work-related laboratory training studies included: computer skill development (Charness, Schumann, \& Boritz, 1992; Corbin, 1986; Czaja, Hammond, Blascovich, \& Swede, 1989; Egan \& Gomez, 1985; Elias, Elias, Robbins, \& Gage, 1987; Gist, Rosen, \& Schwoerer, 1988; Gomez, Egan, Wheeler, Sharma, \& Gruchacz, 1984; Laier, 1993; Myers \& Conner, 1992; Valasek, 1989; Webster \& Martocchio, 1993; Zandri \& Charness, 1989), reaction time related to job performance (Czaja, 1978; Hoyer et al., 1978/1979), and other work related training studies, such as map reading (Neale, Toye, \& Belbin, 1968). Studies that used extensive practice as a training method were included (Czaja, 1978; Hoyer et al., 1978/1979), but studies that allowed practice only to familiarize participants with a task were not (e.g., Czaja \& Sharit, 1993). Studies using tasks that did not appear to be related to the world of work were excluded. Thus, studies of memory training (e.g., Hartley \& Anderson, 1986; Hybertson, Perdue, \& Hybertson, 1982) and plasticity training in fluid intelligence (e.g., Baltes, Dittman-Kohli, \& Kliegl, 1986) were not included.

Second, studies that evaluated the performance of older adults only were excluded because the age variance would be severely restricted (e.g., Franzke, 1987; Jay \& Willis, 1992; Kaye, Stuen, \& Monk, 1985). Studies assessing performance of children or younger adults only were likewise excluded.

Third, only studies reporting direct training mastery outcome measures (i.e., test score, time to complete a final task, time to complete training) were included. Studies that quantified outcomes as cost-benefit measures, length of unemployment following training, posttraining income, and job performance, for example, were not included (e.g., Saunders, 1990; Somers, 1967; Sparrow \& Davies, 1988).

Fourth, the same data were sometimes reported in more than one study. For example, we did not include data from Martocchio and Webster (1992) because the same data were reported in Webster and Martocchio (1993). The data reported in Gomez, Egan, and Bowers (1986) were not included because the same data were reported in Egan and Gomez (1985). Similarly, studies often reported the results of more than one training program. In some cases, the reported effect sizes were calculated from nonindependent samples (e.g., a trainee may have taken more than one course). For those studies reporting nonindependent samples, only one effect size (i.e., the training sample with the largest sample size) was included in the meta-analysis. Observations that appeared to violate the independence of samples assumption were not included (e.g., E. Belbin, 1964; E. Belbin \& Serjean, 1963; Tannenbaum \& Grenholm, 1963).

Fifth, studies reporting the relationship between training outcome and age were included only if a correlation coefficient or a $d$ effect size could be calculated ( see Appendix B for details on the formulas used to calculate effect sizes). Studies that did not report the statistics necessary for calculating a correlation coefficient or $d$ statistic were not used (e.g., Ansley \& Erber, 1988; Bartholomew, 1987; McNeely, 1991; Ryan, Szechtman, \& Bodkin, 1992).

If studies reported more than one type of outcome measure (e.g., test score and time to complete training), both outcome measures were recorded and analyzed separately. For those studies reporting means and variances for three or more groups (Czaja et al., 1989; Elias et al., 1987 ; K. R. Smith, 1938), we pooled groups and treated these effect sizes as dichotomized continuous variables (see Appendix B). Studies sometimes reported more than one effect size for a particular type of outcome measure (e.g., three test scores). In these cases the effect sizes were averaged into a single correlation (Hoyer et al., 1978/1979; Morrow, Yesavage, Leirer, \& Tinklenberg, 1993) that was then entered into the meta-analysis ( see Appendix B). (See Appendix C for a summary of these studies.)

\section{Classification of Effect Sizes}

Correlation coefficients and $d$ s were classified along three dimensions: (a) the type of training criterion measure, (b) the content of the training, and (c) sample characteristics. These dimensions were used to structure the conduct and presentation of the analyses. In addition, we viewed these dimensions as potentially useful in explaining the variance across studies in the age and training performance relationship.

Type of training criteria. Three categories of training outcome criteria were used: (a) training mastery scores, (b) time to complete the final task, (c) and time to complete training (refer to Appendix $\mathrm{C}$ for studies included in each category). Training mastery scores were training criteria that assessed the degree of knowledge or skill mastered. When coding training mastery data, if a study reported both a test score and a count of errors on a final training task, only the posttraining test score was coded as a training mastery measure. When test score was not available but a count of errors on a final training task was reported, the inverse of the error score on a final task was coded as a training mastery score (Czaja, 1978; Egan \& Gomez, 1985; Gomez et al., 1984; Kluge, 1988; Tannenbaum \& Grenholm, 1963). The second type of outcome measure was the time to complete a final task. For instance, Hoyer et al. $(1978 / 1979)$ assessed the number of editing marks completed in $30 \mathrm{~s}$ in a study that aimed to improve response speed. Time to complete final task for computer training was self-paced (Czaja et al., 1989; Egan \& Gomez, 1985; Elias et al., 1987; Gomez et al., 1984; Kluge, 1988; Leonard \& Newman, 1965; Valasek, 1989), and for speeded tests it was timed (Czaja, 1978; Hoyer et al., 1978/1979). Time to complete the training program was the third type of outcome variable; this variable was self-paced. Zandri and Charness (1989), for example, provided a self-paced environment in which participants received instruction in using computer software. The amount of time to complete the training program was recorded.

Content of training. We believe that training content might moderate the relationship between age and training performance. Therefore we sought to develop a taxonomy of training content. The available studies permitted distinction of two categories. Training content was coded as computer (e.g., using software) or other (e.g., training in other job-related skills). Laier (1993), for example, trained younger and older adults in the use of a word-processing program. Barber (1965) trained workers in various maintenance skills (e.g., scaffolding, spray gun use; refer to Appendix $\mathrm{C}$ for study descriptions).

Sample characteristics. Last, effect sizes were coded as either from field or laboratory samples ( see Appendix C). For field training, study participants were employed (e.g., Downs, 1968) or engaging in training for employment (e.g., E. Belbin \& Serjean, 1963). Studies involving laboratory tasks similar to work tasks were coded as laboratory training (e.g., Corbin, 1986). Study participants in laboratory training were typ- 
Table 1

Analysis Results for Correlations Between Age and Training Outcome by

Training Outcome Measure, Training Content, and Type of Sample

\begin{tabular}{|c|c|c|c|c|c|c|c|}
\hline \multirow[b]{2}{*}{ Distribution } & \multirow[b]{2}{*}{ No. of $r$ s } & \multirow[b]{2}{*}{$N$} & \multicolumn{2}{|c|}{$\begin{array}{c}\text { Observed } \\
\text { distribution }\end{array}$} & \multicolumn{3}{|c|}{ Population distribution } \\
\hline & & & Mean $r$ & $\sigma$ & Mean $\rho$ & $\sigma_{\rho}$ & $\begin{array}{l}95 \% \text { credibility } \\
\text { interval }\end{array}$ \\
\hline \multicolumn{8}{|c|}{ Training outcome measures by sample characteristics } \\
\hline $\begin{array}{l}\text { Training mastery score } \\
\text { Field samples } \\
\text { Laboratory samples } \\
\text { Time to complete task } \\
\text { Time to complete training } \\
\text { Field samples } \\
\text { Laboratory samples }\end{array}$ & $\begin{array}{r}48 \\
31 \\
17 \\
9 \\
5 \\
2 \\
3\end{array}$ & $\begin{array}{r}4,389 \\
3,498 \\
891 \\
842 \\
194 \\
77 \\
117\end{array}$ & $\begin{array}{r}-.22 \\
-.21 \\
-.25 \\
.27 \\
.40 \\
.52 \\
.33\end{array}$ & $\begin{array}{l}0.16 \\
0.14 \\
0.20 \\
0.13 \\
0.18 \\
0.01 \\
0.19\end{array}$ & $\begin{array}{r}-.26 \\
-.25 \\
-.29 \\
.28 \\
.42 \\
.56 \\
.33\end{array}$ & $\begin{array}{l}0.14 \\
0.13 \\
0.18 \\
0.09 \\
0.14 \\
0.00 \\
0.15\end{array}$ & $\begin{array}{r}-0.53-0.01 \\
-0.51-0.01 \\
-0.64-0.06 \\
0.10-0.46 \\
0.15-0.69 \\
0.56-0.56 \\
0.04-0.62\end{array}$ \\
\hline \multicolumn{8}{|c|}{ Training content nested within training outcome measure by sample characteristics } \\
\hline $\begin{array}{l}\text { Training mastery score } \\
\text { Computer } \\
\text { Field samples } \\
\text { Laboratory samples } \\
\text { Job-related } \\
\text { Field samples } \\
\text { Laboratory samples }\end{array}$ & $\begin{array}{r}15 \\
2 \\
13 \\
33 \\
29 \\
4\end{array}$ & $\begin{array}{r}868 \\
112 \\
756 \\
3,521 \\
3,386 \\
135\end{array}$ & $\begin{array}{l}-.21 \\
-.04 \\
-.23 \\
-.22 \\
-.21 \\
-.37\end{array}$ & $\begin{array}{l}0.20 \\
0.02 \\
0.20 \\
0.14 \\
0.14 \\
0.18\end{array}$ & $\begin{array}{l}-.23 \\
-.05 \\
-.26 \\
-.26 \\
-.26 \\
-.43\end{array}$ & $\begin{array}{l}0.18 \\
0.00 \\
0.18 \\
0.13 \\
0.13 \\
0.12\end{array}$ & $\begin{array}{l}-0.58-0.12 \\
-0.05--0.05 \\
-0.61-0.09 \\
-0.52--0.01 \\
-0.52--0.01 \\
-0.67--0.20\end{array}$ \\
\hline $\begin{array}{l}\text { Time to complete final task } \\
\text { Computer } \\
\text { Time to complete training }\end{array}$ & 7 & 389 & .31 & 0.17 & .31 & 0.12 & $0.08-0.55$ \\
\hline $\begin{array}{l}\text { Computer } \\
\text { Job-related }\end{array}$ & $\begin{array}{l}3 \\
2\end{array}$ & $\begin{array}{r}117 \\
77\end{array}$ & $\begin{array}{l}.33 \\
.52\end{array}$ & $\begin{array}{l}0.19 \\
0.01\end{array}$ & $\begin{array}{l}.33 \\
.56\end{array}$ & $\begin{array}{l}0.15 \\
0.00\end{array}$ & $\begin{array}{l}0.04-0.62 \\
0.56-0.56\end{array}$ \\
\hline
\end{tabular}

ically community-dwelling older and younger adults or college students. We note that our field versus laboratory distinction is not fully independent from our training content taxonomy. For example, training content focusing on computer skills is much more common in laboratory studies than in field studies.

\section{Results}

\section{Overall Relationship Between Age and Training}

The results of the meta-analysis of age and training performance correlations are presented in Table 1 . The first column in Table 1 describes the distribution being analyzed. The next two columns show the number of correlations on which each distribution was based and the total sample size. The next two columns describe the observed distribution and list the mean and standard deviation. The last four columns present data on the estimated population distribution. We present the mean and standard deviation of the population distribution and the lower and upper bounds of the $95 \%$ credibility interval.

The results of the meta-analysis of age and training performance $d$ effect sizes are presented in Table 2 . The first column in Table 2 describes the distribution being analyzed. The next two columns show the number of $d$ effect sizes on which each distribution was based and the total sample size. The next two columns present the mean and standard deviation of the observed distribution. The last four columns present data on the estimated population distribution. We present the mean and standard deviation of the population distribution and the lower and upper bounds of the $95 \%$ credibility interval.
The results presented for the population distributions are offered as the best estimate of the age and training performance relationship. These population estimates will be the focus of our narrative summary of the results.

\section{Analyses by Training Outcome Measures}

Training mastery scores. Forty-eight correlations with 4,389 observations entered into the analysis of age and training mastery data (see Table 1). The mean correlation between age and training mastery was - -26 . Training mastery test scores decreased as age increased.

When older and younger adults were contrasted in regard to training mastery scores, the results also favored younger adults (see Table 2). The mean difference between the older and younger groups was -0.88 . An effect size can be expressed as a difference in percentiles. With a mean $d$ of -0.88 , if the younger adults were at the 50 th percentile, then older adults would be at the 19 th percentile.

Time to complete final task. The mean correlation between age and outcome, defined as time to complete a posttraining task, was .28. Nine correlations with 842 observations entered into the analysis ( see Table 1). Older adults needed more time to complete the final outcome task than did younger adults. When younger and older adults were contrasted (see Table 2), the results favored young adults. With a mean $d$ of 1.53 , if younger adults were at the 50 th percentile, the older adults would be at the 6 th percentile. 
Table 2

Analysis Results for Effect Sizes by Age Groups for Training Outcome by Training Outcome Measures, Training Content, and Type of Sample

\begin{tabular}{|c|c|c|c|c|c|c|c|}
\hline \multirow[b]{2}{*}{ Distribution } & \multirow[b]{2}{*}{ No. of $d \mathrm{~s}$} & \multirow[b]{2}{*}{$N$} & \multicolumn{2}{|c|}{$\begin{array}{c}\text { Observed } \\
\text { distribution }\end{array}$} & \multicolumn{3}{|c|}{ Population distribution } \\
\hline & & & Mean $d_{o}$ & $\sigma_{d_{\mathrm{o}}}$ & Mean $d$ & $\sigma_{d}$ & $\begin{array}{l}95 \% \text { credibility } \\
\text { interval }\end{array}$ \\
\hline \multicolumn{8}{|c|}{ Training outcome measures by sample characteristics } \\
\hline $\begin{array}{l}\text { Training mastery score } \\
\text { Field studies } \\
\text { Laboratory studies } \\
\text { Time to complete task } \\
\text { Time to complete training }\end{array}$ & $\begin{array}{r}11 \\
2 \\
9 \\
3 \\
7\end{array}$ & $\begin{array}{r}636 \\
83 \\
553 \\
154 \\
395\end{array}$ & $\begin{array}{r}-0.79 \\
-0.34 \\
-0.86 \\
1.53 \\
1.39\end{array}$ & $\begin{array}{l}0.37 \\
0.20 \\
0.35 \\
1.07 \\
0.52\end{array}$ & $\begin{array}{r}-0.88 \\
-0.38 \\
-0.96 \\
1.53 \\
1.39\end{array}$ & $\begin{array}{l}0.29 \\
0.00 \\
0.25 \\
1.02 \\
0.42\end{array}$ & $\begin{array}{l}-1.44--0.32 \\
-0.38--0.38 \\
-1.44--0.47 \\
-0.47-3.54 \\
0.56-2.22\end{array}$ \\
\hline \multicolumn{8}{|c|}{ Training content nested within training outcome measure } \\
\hline $\begin{array}{l}\text { Training mastery test score } \\
\text { Computer } \\
\text { Job-related }\end{array}$ & $\begin{array}{l}9 \\
2\end{array}$ & $\begin{array}{r}553 \\
83\end{array}$ & $\begin{array}{l}-0.86 \\
-0.34\end{array}$ & $\begin{array}{l}0.35 \\
0.20\end{array}$ & $\begin{array}{l}-0.96 \\
-0.38\end{array}$ & $\begin{array}{l}0.25 \\
0.00\end{array}$ & $\begin{array}{l}-1.44--0.47 \\
-0.38--0.38\end{array}$ \\
\hline $\begin{array}{l}\text { Time to complete task } \\
\text { Computer } \\
\text { Time to complete training } \\
\text { Computer }^{2}\end{array}$ & 2 & 124 & 1.01 & 0.02 & 1.01 & 0.00 & $1.01-1.01$ \\
\hline
\end{tabular}

all studies used laboratory samples.

Time to complete the training program. The mean correlation between age and training outcome, defined as the time to complete the training program, was .42 . Older adults took longer than young adults to complete the training program. Five correlations with a total of 194 observations entered into the analysis ( see Table 1). In the extreme-groups analyses (see Table 2$)$, the age differences were also substantial $(d=1.39)$. The older adults took more time to complete the training program. If the younger adults were at the 50th percentile, then the older adults would be at the 8 th percentile.

\section{Relationships Between Age and Training Outcome by Task Content Nested Within Training Outcome Measure}

Only cells with two or more observations were included in the subsequent analyses. The meta-analysis results of the correlational subdistribution analyses are presented in Table 1, and the $d$ subdistribution analyses are presented in Table 2 .

Training mastery scores for computer and noncomputer training. The mean correlation between age and training mastery scores for computer training was -.23 . Older adults had lower mastery of the training content than younger adults. When the training content was job related, the negative age effect on performance was slightly greater $(r=-.26)$. Fifteen and 33 correlations with 868 and 3,521 observations entered into these analyses, respectively ( see Table 1 ).

The age differences between older and younger adults also were substantial ( see Table 2). For computer training, the mean $d$ was -0.96 . If young adults performed at the 50 th percentile, then older adults performed at the 17 th percentile. The age differences were greatly reduced for job-related training, mean $d=-0.38$. Thus, if young adults were at the 50 th percentile, then older adults were at the 35 th percentile.
Time to complete the final tasks for computer training. Older adults performed more slowly than younger adults in completing a posttraining task when the training content was computer related $(r=.31)$. The results of the extreme-groups comparisons also indicated age differences ( $d=1.01$; see Table 2 ). If the younger adults were at the 50 th percentile, the older adults would be at the 16 th percentile.

Time to complete computer training. Three correlations with 117 observations entered into the analyses (see Table 1). The correlation between age and time to complete computer software training was .33. Older adults took more time to complete the training. Seven effect sizes with 395 observations entered into the extreme-groups analyses (see Table 2). Older adults took much longer than younger adults to complete training involving computers $(d=1.39)$ when the extreme groups were considered. If the younger adults were at the 50 th percentile, then the older adults would be at the 8 th percentile.

\section{Analyses of Field Versus Laboratory Samples}

The relationship between age and training performance was moderated by the type of sample used in the study. Analyses of the training mastery scores for computer training yielded a mean correlation of -.23 between age and test performance (see Table 1). However, when only field samples were considered, the correlation between age and test performance was substantially reduced $(-.05)$. In contrast, when laboratory samples were used, the mean correlation was much higher $(-.26)$.

Training mastery for job-related training $(r=-.26)$ was also moderated by sample characteristics (see Table 2). Analysis of the laboratory studies yielded a mean correlation of -.43 . Conversely, the mean correlation was substantially smaller when field studies were analyzed $(r=-.26)$. 
A similar pattern was found when extreme-groups effect sizes were considered. For instance, the meta-analysis of training mastery data yielded a mean difference of -0.88 . For a mean $d$ of -0.88 , if the younger adults were at the 50 th percentile then older adults would be at the 19 th percentile. This mean difference was substantially smaller when only field samples were considered $(-0.38)$. Subsequently, older adults would be performing at the 35 th percentile, if the young adults were at the 50 th percentile.

\section{Estimates of Training Performance by Age}

Table 3 presents the mean estimated training performance for several ages. We estimated training performance by using the correlation between age and training mastery $(-.26)$ as the standardized beta weight for age in a regression equation with training performance as the dependent variable. A standardized beta weight requires that one express both training performance and age as standardized variables. Across our samples in actual employment training settings, the mean age was 37 years. Therefore, we used 37 as a reasonable estimate of the mean age in typical employee samples. We estimated the standard deviation of age in typical employee samples to be 10.0 years. The mean age and standard deviation are consistent with the age data of other employment samples, such as the validation samples of the General Aptitude Test Battery (GATB; U.S. Department of Labor, 1970). Our analyses of the GATB data yielded a mean age of 32 and a standard deviation of 10.0 from a database of 133 studies. Whereas the GATB database was assembled in the 1970s, and the mean age of employee samples is increasing with aging of the postwar baby boomers, our estimated value of 37 years is reasonable. Additional data support our estimate of the age standard deviation. A. A. Sterns, Marsh, and McDaniel (1994) reported an average standard deviation of 10.3 years across a large data set of employee samples. We set the 50th percentile of training performance at the expected training performance of the 37-year-olds.

Table 3

Estimated Mean Training Performance by Age

\begin{tabular}{ll}
\hline Age & $\begin{array}{c}\text { Estimated } \\
\text { performance percentile }\end{array}$ \\
\hline 20 & 67 th \\
25 & 62 nd \\
30 & 57 th \\
35 & 52 nd \\
37 & 50 th \\
40 & 47 th \\
45 & $42 \mathrm{nd}$ \\
50 & 37 th \\
55 & $32 \mathrm{nd}$ \\
60 & 28 th \\
65 & 23 rd \\
70 & 20 th \\
\hline
\end{tabular}

Note. Table sets the 50 th percentile of performance at age 37 , the approximate mean age of the work force. The standard deviation of age was set to 10 , a typical standard deviation of age in employee samples. The correlation between age and training mastery $(-.26)$ was used as the standardized beta weight for age.
We offer the data in Table 3 as reasonable estimates of mean level training mastery by age. The differences are fairly striking and substantially unfavorable for the older employee. For example, the average 25 -year-old will be at the 62 nd percentile at the end of training compared with the $23 \mathrm{rd}$ percentile for the average 65 -year-old. We do not deny that there will be substantial individual differences and recognize that variance in performance for older adults tends to be larger than in the performance of younger adults. Thus, some older adults will show equal or greater mastery of training content than most younger adults. However, on average, one can expect substantial age differences in the mastery of training content.

We speculate that older adults will show less mastery of training content because of at least two factors. First, older adults may have begun training with a disadvantage. This disadvantage might involve less pretraining mastery of the training material. Thus, even if older and younger adults learn the same number of training content units during training (i.e., have equal training gain scores), older adults would show less mastery of the training material content. Second, older adults may learn less during training than younger adults. In this scenario, the older adults will have smaller gain scores than younger adults. The extant literature has little data to address the relative importance of these factors. Below we summarize these limited data.

Analysis of pretest group differences. Older adults may have lower mastery of training content than younger adults, if they have less pretraining mastery. Only five samples from three studies (Corbin, 1986; Dodd, 1967; Neale et al., 1968), with a total sample size of 280 individuals, permitted a comparison of the age effects on a pretest score. The mean correlation was -.21 , suggesting that the older adults have less mastery than the younger adults before training.

Within-group gain scores. An analysis of gain scores would be a direct test of how much each age group benefited from training. The calculation of a gain score effect size requires the correlation between the pretest and the posttest. As noted, few studies had a pretest, and none provided correlations between pretest and posttest scores. However, four studies did report pretest-posttest differences (i.e., gain scores), with a total of 857 observations (Carter, 1985; Corbin, 1986; Dodd, 1967; Winkle, 1991). The correlation between age and gain scores was -.09 , suggesting that older adults benefited slightly less from training.

In work settings, pretraining differences are irrelevant to the question of whether older and younger adults can achieve the same level of proficiency at the end of training. If older workers are less proficient at the end of training, the employer has a problem regardless of whether the difference is due to age differences in learning or to age-related pretest differences. If older adults have lower levels of job knowledge due to less mastery of training material, one can expect their job performance to be lower than that of younger adults (Dye, Reck, \& McDaniel, 1993).

\section{Discussion}

Age was negatively related to training material mastery ( $r=$ -.26 ), with poorer performance associated with increased age. Age was positively associated with time to complete final tasks 
( $r=.28)$ and with time to complete training $(r=.42)$. The training participants tended to perform the final outcome measure more slowly with increased age, and they also took more time to master the training content.

The correlation between age and training outcome differed depending on the type of training outcome measure used. The absolute magnitude of the correlation for time to complete the final task ( $r=.28)$ was about the same as for the training mastery measures $(r=-.26)$. A larger age effect $(r=.42)$ was found for time to complete training.

The age effect also was evident when extreme groups (i.e., older and younger adults) were compared. Older adults scored lower than younger adults on training content mastery measures $(d=-0.88)$. They completed posttraining tasks much more slowly ( $d=1.53$ ), and they took longer to complete the training program $(d=1.39)$ than did younger adults.

For the extreme-groups analyses, age group differences were larger ( $d=-0.96)$ when the training content concerned computer use than when training content involved (noncomputer) job-related skills ( $d=-0.38$ ). Thus, we estimated that older adults were performing at the 17 th percentile for computer skills training, whereas for training on job-related skills, older adults were at the 35 th percentile. Furthermore, the computer training studies were laboratory studies in contrast to the jobrelated training studies that typically used field samples. The correlational data showed smaller differences in coefficients between computer and noncomputer training. Because training content is largely confounded with whether the study was a laboratory study or a field study, we are hesitant to conclude that the age and training performance relationship is moderated by training content. Conclusions in this area are best drawn once additional data are collected in future primary research.

Laboratory samples tended to show larger age differences in training performance than field samples. In many of the laboratory-based studies, the purpose of the study was to examine age differences. We suspect that the training content was often chosen to maximize age differences. In most real-world tasks, however, there is probably greater opportunity for effects of practice and experience to counter age-related decrements (Charness \& Bosman, 1990; Salthouse, 1990). Therefore, we suggest that the results based on field studies are the best estimates of age effects in typical work settings.

The credibility intervals for the population distributions presented in Tables 1 and 2 are large enough to warrant additional examination. Specifically, our analyses have not fully explained why the age differences are larger for some studies than for others. Because we corrected for sampling error and differences across studies in range restriction for the correlational data, we have likely corrected for the major sources of artifactual variance. Thus, the remaining variance can primarily be attributed to moderators. Our results suggest that some of the variance across studies can be attributed to whether the samples were laboratory or field. Similarly, the content of the training may be related to the magnitude of the age differences. Yet substantial variance remains unexplained in most of the distributions. Here we offer hypotheses that can be tested when more studies explaining age differences in training outcomes have accumulated. The existing data set does not support testing of these hypotheses because of the relatively small number of studies available, and because most of the studies did not report the necessary data for classification with respect to the moderators. We offer four categories of moderators that deserve additional research attention.

First, we argue that there are other sample characteristics beyond the field versus laboratory distinction that may be responsible for varying magnitudes of age correlates with training outcomes. Specifically, the age-and-training-outcome relationships may vary across studies with the magnitude of variables correlated with age. For example, if the younger adults in a sample were cognitively gifted college students and the older adults were drawn from nursing homes, then one would expect larger age effects than if both the younger and older adults were drawn from a population of employed adults with similar levels of education. The variance of age in the samples will also affect the magnitude of the differences. Samples with large age variances, on average, will yield larger training-age correlates than samples with small age variances. In the analyses of the effect sizes expressed as correlation coefficients, we corrected for differences across studies in age variance where the age variable had been dichotomized, and thus these differences do not contribute to the population variance. However, for the effect sizes expressed as standardized mean differences such corrections are not possible. Therefore, the differences across studies in age variances likely affect the magnitude of the age-and-training relationship. For example, contrasts between 18-year-olds and 80year-olds will, on average, yield larger training differences than contrasts between 30 -year-olds and 50 -year-olds.

Second, we suggest that the variance across studies in the strength of training will explain variance across studies in the magnitude of the age-and-training-outcome relationship. Length of training is one operational definition of training strength. It is possible that longer training interventions will yield greater age effects in age-and-training-outcome relationships than shorter training interventions. Amount of information conveyed in training is an additional measure of training strength. Training programs that aim for large increments in trainees' knowledge level may show greater age-and-training effects than training programs with more modest goals. The efficacy of training delivery is a third indicator of strength of training. If the delivery of training materials is very poor such that no one masters the training, there will be no age differences.

Third, the type of training method used may have affected the variance in the age and training outcomes. A variety of training techniques have been used, including activity learning, classroom instruction, the sit-by-me approach, modeling, on-the-job training, programmed instruction, self-paced instruction, selfefficacy enhancement, and practice. Also, some methods may be more effective for trainees in one age group than another (H. L. Sterns, 1986; H. L. Sterns \& Alexander, 1987; H. L. Sterns \& Doverspike, 1989). Thus, the different training methods may yield varying levels of age correlates.

Fourth, we argue that the varying training mastery measures have probably contributed to the variance in the age-and-training outcomes across studies. Although all the training mastery measures may be classified as learning outcomes, they comprise a diverse set. Similarly, the difficulty levels of the mastery measures will likely affect the magnitude of the age-and-training mastery relationship. Training outcome measures that are very 
difficult, meaning that most or all the trainees exhibit little mastery, will show small age correlates because of the range restriction on the mastery measures. Similarly, training mastery measures that are very easy, meaning that most or all trainees show complete mastery, will also have range restriction resulting in low age correlates. Diversity in the content of the training mastery measures and differences across studies in the difficulty of the training mastery measures are potential moderators of the age and mastery relationship. These variables should be explored as sufficient data accumulate to allow such analyses.

In summary, although older adults on average have less mastery of trained material at the end of training than do younger adults, the relationship varies across studies. Additional research, with a larger pool of studies, needs to replicate the moderators examined in this study and the potential moderators suggested above. Although the amount of unexplained variance highlights the need for additional research, it does not invalidate our conclusions that older workers have less mastery of trained material and take longer to complete training. Although the credibility intervals are wide, most of the effect sizes in the population distributions are negative for the age-and-trainingmastery relationship and positive for the age-and-time-indices relationships. Thus, although the magnitude of the relationship varies somewhat across studies, older adults, on average, can be expected to have less mastery at the end of training than younger adults. Similarly, although the magnitude of the relationship can be expected to vary somewhat, older adults on average will take longer than younger adults to complete training.

\section{Considerations When Interpreting the Results of the Present Study}

Although we believe that our results strongly support our conclusions that older workers have less mastery of trained material and take longer to complete training, we offer several issues that should be considered when interpreting the results. First, some analyses (e.g., time to complete final task, time to complete training, and several subdistribution moderator analyses ) are based on distributions containing few studies. Distributions with few effect sizes have greater potential for secondorder sampling error, which can distort population effect size variance estimates and, to a lesser extent, distort estimates of mean population effect sizes (Hunter \& Schmidt, 1990; F. L. Schmidt, Hunter, Pearlman \& Hirsh, 1985, Questions and Answers Number 25). Therefore, these analyses should be rerun in the future as more studies become available.

The second consideration is study design. Some studies report data on continuous or dichotomized continuous age distributions, whereas others report results of extreme-groups age comparisons. The latter are an accurate representation of the differences between younger and older adults, but these effect sizes are overestimates of the relationship between age as a continuous variable and training performance.

Third, the results must be interpreted with caution because of the probable pretraining differences between the younger and older adults. What little data that are available indicate that the older adults perform substantially worse on pretraining tests than the younger workers. Thus, it may be that older adults benefit from training as much as younger adults and that the train- ing outcome differences reflect pretraining differences. Therefore, although we suspect that it is true, our results do not support a strong statement that adults learn less in training. Rather, our results provide reasonably strong evidence that at the conclusion of training, adults show less mastery of the training content. It is also clear that adults take longer to complete the training. However, regardless of whether the age difference is due to age-related differences in learning the training content or to age-related pretraining differences, employers are faced with the problem of age-related differences in the mastery of the training content. Still, more research is needed to clarify the source of the posttraining mastery differences.

Fourth, our training mastery criteria are limited to learning measures collected at the end of training. Other criteria, such as behavioral change, also are important and have received little attention in studies addressing age and training mastery. In addition, R. A. Schmidt and Bjork (1992) persuasively argued that training criteria should examine the extent of learning or skills that are retained and generalized at some point past the end of training (e.g., 3 months after training). Again, few training studies addressing age have incorporated distal criteria.

Fifth, we argue against the overinterpretation of age correlates of training time. Although we have substantial concerns regarding the implications of the age differences in training mastery, we do not believe that the age difference in time to complete training is typically problematic. Consider a scenario where employees are learning a new procedure that they will use for the next 6 months. If younger adults take $4 \mathrm{hr}$ to master the new procedures and older adults take $8 \mathrm{hr}$ to master the new procedures, the additional $4 \mathrm{hr}$ are probably not excessively costly to the employer because the procedures, once learned, will be used for an extended period. However, the training time differences will become more costly to the employer if training is needed frequently. In this situation, the cumulative costs of the additional time could become substantial.

Sixth, our results, when considered in conjunction with the age-and-job-performance literature, present a paradox. The present results suggest that older adults have less mastery of training material at the end of training than do younger adults. As new procedures replace old work procedures, one would expect the job performance of the older worker to become less effective relative to the job performance of the younger workers. Yet the research on the relationship between age and job performance consistently shows older workers performing as well as younger workers (Avolio et al., 1990; McEvoy \& Cascio, 1989; Waldman \& Avolio, 1986). Although the resolution of this paradox is beyond the scope of this article, we offer two possible scenarios.

One scenario is that although older workers might have less mastery at the end of training, they may gain mastery of the new work procedures on the job. This scenario suggests that older workers will have lower performance than their younger counterparts until the needed procedures are learned. The performance measures used in the age-and-job-performance studies may be insensitive to the job performance differences during the periods of older worker skill acquisition. For example, if supervisory performance appraisals are conducted once a year, they may not capture the performance differences over a several- 
week time span when the older worker was gaining skills already learned by the younger worker.

A second scenario is that past review studies have ignored or nonoptimally examined occupational moderators of the ageand-job-performance relationships. Thus, jobs that require frequent skill updating through training may show a gradual decline in the job performance of older workers. However, older workers may have better job performance than younger workers, if performance benefits from job knowledge are gained through experience. Warr (1994) presented a four-category taxonomy of jobs consistent with this conceptualization. Although previous studies of the age-and-job-performance relationship have attempted to examine occupational moderators (Avolio et al., 1990; McEvoy \& Cascio, 1989; Waldman \& Avolio, 1986), the results have been weak tests of occupational moderators. Simplistic taxonomies, such as classifying jobs as professional or not professional, may not be sensitive enough to find the moderating effects of occupations on the age-and-job-performance relationship.

Our seventh consideration regards the amount of data that could not be considered because of poor reporting in the primary studies. Most studies lacked pretraining assessments, which causes the present study to be weak in terms of pre-post change analyses. In addition, we could not use data from many studies because of the lack of reported statistics. Researchers should become more aware of the importance of reporting critical statistics (e.g., $N$ sizes, chi-squares, $F$ or $t$ values, univariate analyses of variance, means, and standard deviations, etc.). Future research cumulations in this area would be greatly improved with better reporting of data in the primary studies.

\section{Implications and Recommendations}

Our results are consistent with much of the cognitive aging literature and at odds with much of the adult education and training literature. Our results are discussed with respect to these literatures. The poor showing of older workers in our data set is consistent with much of the cognitive aging literature (e.g., Salthouse, 1985) that indicates that age differences are substantial when speed of performance is assessed. Speed of cognitive processing may underlie age differences in training performance to a large extent (e.g., Cerella, 1990; Salthouse, 1985; Warr, 1994). For example, reduced information-processing resources often result in poorer performance on tasks that require speed or multiple processing resources. Older adults may miss relevant details of the training program because of slower processing rates and a reduced working memory capacity, leading to poorer comprehension of material (Forteza \& Prieto, 1994; Warr, 1994).

Our results are somewhat at odds with the current adult education and training literature that emphasizes that individuals can learn and benefit from education and training at all points in the lifespan (H. L. Sterns, 1986; Willis, 1985). Our data suggest that at the end of training, older adults will have less mastery of the training material than younger adults. At least part of this age effect may be due to pretraining differences in mastery. However, even if one accepts that the age differences in training mastery measures reflect age-related differences in the ability to benefit from training, one cannot make the claim that all older adults benefit less from training than younger adults. Larger variance for older adults than younger adults was shown for the 35 of the 43 samples reporting outcome measure variance data by age. This suggests greater individual differences in older than in younger adults. Thus, although most older adults did not benefit as much as younger adults from training, some older adults improved as much or more than younger adults. Still, the average difference in training mastery is large enough to have substantial consequences for employers.

The need for studies of training methods appropriate for older workers cannot be overemphasized. With gains in life expectancy, the aging of the baby boomers, and legislative protection for older workers, we can expect the numbers of older workers to increase. The need for effective training methods becomes even more important if skill obsolescence is considered. H. L. Sterns and Doverspike ( 1989) estimated that in some jobs, skills become obsolete after 5 years because of technological changes. As such, it is important to update the knowledge and skills of all workers regardless of age.

\section{Conclusion}

This article has summarized the available literature concerning age differences in training performance. Older adults have less mastery of the training content than younger adults, and they require more time to cover the training material. We have offered various caveats to our conclusions that need to be closely considered when interpreting these results. One of these caveats concerns the relatively few studies investigating the age-andtraining-performance relationship. Given the serious implications of the present results, additional research is clearly warranted.

\section{References}

References marked with an asterisk indicate studies included in the meta-analysis.

ABI/Inform ondisc [Database]. (1971, January-1994, December). Ann Arbor, MI: University Microfilm.

Ansley, J., \& Erber, J. T. (1988). Computer interaction: Effect on attitudes and performance in older adults. Educational Gerontology. 14, 107-119.

Avolio, B. J., Waldman, D. A., \& McDaniel, M. A. (1990). Age and work performance in nonmanagerial jobs: The effects of experience and occupational type. Academy of Management Journal, 33, 1-16.

Baltes, P. B., Dittman-Kohli, F., \& Kliegl, R. (1986). Reserve capacity of the elderly in aging-sensitive tests of fluid intelligence: Replication and extension. Psychology and Aging, 1, 172-177.

${ }^{*}$ Barber, J. W. (1965). Training the middle aged worker. Job re-design and occupational training for older workers (supplement to the final report). Paris: Organization for Economic Cooperation and Development.

Bartholomew, S. (1987). Retraining decisions of older displaced workers. Unpublished doctoral dissertation, University of California, Los Angeles.

*Belbin, E. (1958). Methods of training older workers. Ergonomics, 1 , 208-221.

*Belbin, E. (1964). Training the adult worker. London: Her Majesty's Stationery Office.

Belbin, E., \& Belbin, R. M. ( 1972). Problems in adult retraining. London: Heineman.

*Belbin, E., \& Serjean, R. (1963). Training in the clothing industry: 
A study of recruitment, training and education. London: Twentieth Century Press.

*Belbin, R. M. (1969). The discovery method: An international experiment in retraining. Paris: Organization for Economic Co-operation and Development.

Carter, J. O. (1985). The effectiveness and feasibility of short-term interpersonal communication training for a heterogeneous population of employed adults. Unpublished doctoral dissertation, University of Maryland, Baltimore.

Cerella, J. (1990). Aging and information-processing rate. In J. E. Birren \& K. W. Schaie (Eds.), Handbook of the psychology of aging (3rd ed., pp. 201-221). New York: Academic Press.

Charness, N., \& Bosman, E. A. (1990). Expertise and aging: Life in the lab. In T. H. Hess (Ed.), Aging and cognition: Knowledge organization and utilization (pp. 343-385). Amsterdam: Elsevier.

${ }^{*}$ Charness, N., Schumann, C. E., \& Boritz, G. M. (1992). Training older adults in word processing: Effects of age, training technique, and computer anxiety. International Journal of Technology \& Aging, $5,79-106$.

*Corbin, W. J. (1986). The effects of age, attitude, and sex on the performance of adults in computer-based learning experiences. Unpublished doctoral dissertation, George Peabody College for Teachers, Vanderbilt University.

Craik, F. I. M., \& McDowd, J. M. (1987). Age differences in recall and recognition. Journal of Experimental Psychology: Learning, Memory, and Cognition, 13, 474-479.

*Czaja, S. J. (1978). Varying training techniques across age groups for a visual inspection task. Unpublished manuscript.

*Czaja, S. J., Hammond, K., Blascovich, J. J., \& Swede, H. (1989). Age related differences in learning to use a text-editing system. Behaviour and Information Technology, 8, 309-319.

Czaja, S. J., \& Sharit, J. (1993). Age differences in the performance of computer-based work. Psychology and Aging, 8, 59-67.

Dissertation Abstracts (1985, January-1994, December). Ann Arbor, MI: University Microfilm.

*Dodd, B. (1967). A study in adult retraining: The gas man. Occupational Psychology, 41, 143-153.

*Downs, S. (1968). Selecting the older trainee, a pilot study of trainability tests. National Institute of Industrial Psychology Bulletin, 14. 19-26.

Dye, D. A., Reck, M., \& McDaniel, M. A. (1993). Moderators of the validity of written job knowledge measures. International Journal of Selection and Assessment, 1, 153-157.

Educational Resources Information Center (ERIC) [Database] . (1982, January-1994, December). Wellesley Hills, MA: Silver Platter.

*Egan, D. E., \& Gomez, L. M. (1985). Assaying, isolating, and accommodating individual differences in learning a complex skill. In R. F. Dillon (Ed.), Individual differences in cognition (Vol. 2, pp. 173-217). San Diego, CA: Academic Press.

*Elias, P. K., Elias, M. F., Robbins, M. A., \& Gage, P. (1987). Acquisition of word-processing skills by younger, middle-age, and older adults. Psychology and Aging, 2, 340-348.

*Entwisle, D. G. (1959). Ageing: The effects of previous skill on training. Occupational Psychology, 33, 238-243.

Forteza, J. A., \& Prieto, J. M. (1994). Aging and work behavior. In H. C. Triandis, M. D. Dunnette, \& L. H. Hough (Eds.), Handbook of industrial and organizational psychology (2nd ed., Vol. 4, pp. 447483). Palo Alto, CA: Consulting Psychologists Press.

Franzke, A. P. (1987). The effects of assertiveness training on older adults. The Gerontologist, 27, 13-16.

*Giannetto, P. W. (1993, April). The effects of age and self-efficacy on training and job performance in an applied setting. Paper presented at the Eighth Annual Convention of the Society of Industrial and Organizational Psychology, San Diego, CA.
Giniger, S., Dispenzieri, A., \& Eisenberg, J. (1983). Age, experience and performance on speed and skill jobs in an applied setting. Journal of Applied Psychology, 68, 469-475.

${ }^{*}$ Gist, M., Rosen, B., \& Schwoerer, C. (1988). The influence of training method and trainee age on the acquisition of computer skills. Personnel Psychology, 41, 255-265.

Glass, G. V., McGaw, B., \& Smith, M. L. (1981). Meta-analysis in social research. Beverly Hills, $\mathrm{CA}$ : Sage.

Gomez, L. M., Egan, D. E., \& Bowers, C. (1986). Learning to use a text editor. Human-Computer Interactions, 2, 1-23.

${ }^{*}$ Gomez, L. M., Egan, D. E., Wheeler, E. A., Sharma, D. K., \& Gruchacz, A. M. (1984). How interface design determines who has difficulty learning to use a text editor. In A. Janda (Ed.), Human factors in computing systems (pp. 176-181). New York: North-Holland.

Hartley, A. A., \& Anderson, J. W. (1986). Instruction, induction, generation, and evaluation of strategies for solving search problems. Journal of Gerontology, 41, 650-658.

Hasher, L., \& Zacks, R. T. (1979). Automatic and effortful processes in memory. Journal of Experimental Psychology: General, 108, 356388.

Hasher, L., \& Zacks, R. T. (1988). Working memory, comprehension, and aging. A review and a new view. In G. H. Bower (Ed.), The psychology of learning and motivation (Vol. 22, pp. 193-225). New York: Academic Press.

Hays, W. L. (1988). Statistics (4th ed.). New York: Holt, Rinehart and Winston.

*Hoyer, F. W., Hoyer, W. J., Treat, N. J., \& Baltes, P. B. (1978/1979). Training response speed in young and elderly women. International Journal of Aging and Human Development, 9, 247-253.

*Hughes, J. L., \& McNamara, W. J. (1961). A comparative study of programmed and conventional instruction in industry. Journal of Applied Psychology, 45, 225-231.

Hunter, J. E., \& Schmidt, F. L. (1990). Methods of meta-analysis: Correcting error and bias in research findings. Newbury Park, CA: Sage.

Hybertson, J. P., Perdue, J., \& Hybertson, D. (1982). Age differences in information acquisition strategies. Experimental Aging Research, 8 , 109-113.

Jay, G. M., \& Willis, S. L. (1992). Influence of direct computer experience on older adults' attitudes toward computers. Journal of Gerontology, 47, 250-257.

Kaye, L. W., Stuen, C., \& Monk, A. (1985). The learning and retention of teaching skills by older adults: A time series analysis. Educational Gerontology, 11, 113-125.

Kirk, R. E. (1990). Statistics, an introduction (3rd ed). New York: Holt, Rinehart, and Winston.

*Kluge, E. A. (1988). The relationships of instructional delivery methods and individual differences to the training operators of computer systems. Unpublished doctoral dissertation, Oregon State University.

*Laier, M. P. (1993). Improving training performance of younger and older adults through self-efficacy enhancement. Unpublished doctoral dissertation, University of Akron.

Law, K. S., Schmidt, F. L., \& Hunter, J. E. (1994a). A test of two refinements in procedures for meta-analysis. Journal of Applied Psychology, 79, 978-986.

Law, K. S., Schmidt, F. L., \& Hunter, J. E. (1994b). Non-linearity of range correlations in meta-analysis: A test of an improved procedure. Journal of Applied Psychology, 79, 425-438.

*Leonard, J. A., \& Newman, R. C. (1965). On the acquisition and maintenance of high speed and high accuracy in a keyboard task. Ergonomics, 8, 281-304.

Martocchio, J. J., \& Webster, J. ( 1992). Effects of feedback and cognitive playfulness on performance in microcomputer software training. Personnel Psychology, 45, 553-578.

McDaniel, M. A. (1986). Computer programs for calculating meta- 
analysis statistics. Educational and Psychological Measurement, 46, 175-177.

McDaniel, M. A., Schmidt, F. L., \& Hunter, J. E. (1988). A meta-analysis of methods for rating training and experience in personnel selection. Personnel Psychology, 41, 283-314.

McDowd, J. M., \& Birren, J. E. (1990). Aging and attentional processes. In J. E. Birren \& K. W. Schaie (Eds.), Handbook of the psychology of aging (3rd ed., pp. 222-234). New York: Academic Press.

McEvoy, G. M., \& Cascio, W. F. (1989). Cumulative evidence of the relationship between employee age and job performance. Journal of Applied Psychology, 74, 11-17.

McFarland, R. A. (1953). Human factors in air transportation: Occupational health and safety. New York: McGraw-Hill.

McNeely, E. (1991). Computer-assisted instruction and the older-adult learner. Educational Gerontologist, 17, 229-237.

*Morrow, D., Yesavage, J., Leirer, V., \& Tinklenberg, J. (1993). Influence of aging and practice on piloting tasks. Experimental Aging Research, 19, 53-69.

Murphy, K. R. (1989). Is the relationship between cognitive ability and job performance stable over time? Human Performance, 2, 183-200.

Murrell, K. F. H. (1962). Industrial aspects of aging. Ergonomics, 5, 147-153.

*Myers, C., \& Conner, M. (1992). Age differences in skill acquisition and transfer in an implicit learning paradigm. Applied Cognitive Psychology, 6, 429-442.

*Neale, J. G., Toye, M. H., \& Belbin, E. (1968). Adult training: The use of programmed instruction. Occupational Psychology, 42, 23-31.

Park, D. C. (1992). Applied cognitive aging research. In F. I. M. Craik \& T. A. Salthouse (Eds.), The handbook of aging and cognition (pp. 449-494). Hillsdale, NJ: Erlbaum.

Pearlman, K. (1979). The validity of tests used to select clerical personnel: $A$ comprehensive summary and evaluation (TS-79-1). U.S. Office of Personnel Management, Personnel Research and Development Center, (NTIS No. PB 80. 102650 ).

Psychological Abstracts (1969, January-1983, December). Washington, DC: American Psychological Association.

PsycLIT [Database]. (1983-1995, September). Washington, DC: American Psychological Association [Producer] . Available from: Silver Platter.

Rhodes, S. R. ( 1983) . Age-related differences in work attitudes and behavior: A review and conceptual analysis. Psychological Bulletin, 93, 328-367.

Rosen, B., \& Jerdee, T. H. (1976). The influence of age stereotypes on managerial decisions. Journal of Applied Psychology, 61, 428-432.

Ryan, E. B., Szechtman, B., \& Bodkin, J. (1992). Attitudes toward younger and older adults learning to use computers. Journal of Gerontology: Psychological Sciences, 47, 96-101.

Salthouse, T. A. (1985). A theory of cognitive aging. Amsterdam: North-Holland.

Salthouse, T. A. (1990). Cognitive competence and expertise in aging. In J. E. Birren \& K. W. Schaie (Eds.), Handbook of the psychology of aging (3rd ed., pp. 311-319). New York: Academic Press.

Salthouse, T. A. (1991). Theoretical perspectives on cognitive aging. Hillsdale, NJ: Erlbaum.

Saunders, B. W. (1990). The relationship between job status, in-service training, and specified job outcomes among highway maintenance workers in the North Carolina Department of Transportation. Unpublished doctoral dissertation, North Carolina State University, Raleigh.

Schmidt, F. L., Hunter, J. E., Pearlman, K., \& Hirsh, H. R. (1985). Forty questions and answers about validity generalization and metaanalysis. Personnel Psychology, 38, 697-798.

Schmidt, F. L., Law, K., Hunter, J. E., Rothstein, J. R., Pearlman, K., \& McDaniel, M. A. (1993). Refinements in validity generalization procedures: Implications for the situational specificity hypothesis. Journal of Applied Psychology, 78, 3-13.

Schmidt, R. A., \& Bjork, R. A. (1992). New conceptualizations of practice: Common principles in three paradigms suggest new concepts for training. Psychological Science, 3, 207-217.

*Shooter, A. M., Schonfield, A. E. D., King, H. F., \& Welford, A. T. (1956). Some field data on the training of older people. Occupational Psychology, 30, 204-215.

Smith, B. D. (1990). Human factors and aging: An overview of research needs and application opportunities. Human Factors, 32, 509-526.

*Smith, K. R. (1938). Age and performance on a repetitive manual task. Journal of Applied Psychology, 22, 295-306.

Social Science Citation Index [Database]. (1972-1995, September 6). Philadelphia: Institute for Scientific Information. Available from: DIALOG.

Somers, G. G. (1967). Evaluation of work experience and training of older workers: Methodological considerations in the application of cost-benefit analysis to Title V of the Economic Opportunity Act. Madison: Madison Industrial Relations Research Institute, University of Wisconsin.

Sparrow, P. R., \& Davies, D. R. (1988). Effects of age, tenure, training, and job complexity on technical performance. Psychology and Aging, 3, 307-314.

Sterns, A. A., Marsh, B. A., \& McDaniel, M. A. (1994, April). Age and job satisfaction: A comprehensive review and meta-analysis. Paper presented at the Ninth Annual Conference of the Society of Industrial and Organizational Psychology, Nashville, TN.

Sterns, H. L. (1986). Training and retraining, adult and older adult workers. In J. E. Birren, P. K. Robinson, \& J. E. Livingston (Eds.), Age, health, and employment (pp. 93-113). Englewood Cliffs, NJ: Prentice Hall.

Sterns, H. L., \& Alexander, R. A. (1987). Industrial gerontology: The aging individual and work. Annual Review of Gerontology and Geriatrics, 7, 243-264.

Sterns, H. L., \& Doverspike, D. D. (1989). Aging and the training and learning process. In I. L. Goldstein (Ed.), Training and development in organizations (pp. 299-332). San Francisco: Jossey-Bass.

Szafran, J. (1966). Age differences in the rate of gain of information, signal detection strategy, and cardiovascular status among pilots. Gerontologia, 12, 6-17.

*Tannenbaum, A., \& Grenholm, G. (1963). Older workers' performance in industrial retraining programs. In E. Weinberg (Ed.), Industrial retraining programs for technological change (Bureau of Labor Statistics Bulletin 1368). Washington, DC: U.S. Department of Labor.

U.S. Department of Labor (1970). General Aptitude Test Battery, Section III: Development. U.S. Employment Service. Washington, DC: U.S. Government Printing Office.

*Valasek, D. L. (1989). Young/old differences in training and selfefficacy on computer skills and computer attitudes. Unpublished doctoral dissertation, University of Akron.

Waldman, D. A., \& Avolio, B. J. (1986). A meta-analysis of age differences in job performance. Journal of Applied Psychology, 71, 33-38.

Warr, P. (1994). Age and employment. In H. C. Triandis, M. D. Dunnette, \& L. H. Hough (Eds.), Handbook of industrial and organizational psychology (2nd ed., Vol. 4, pp. 485-550). Palo Alto, CA: Consulting Psychologists Press.

*Webster, J., \& Martocchio, J. J. (1993). Turning work into play: Implications for microcomputer software training. Journal of Management, 19, 127-146.

*Welford, A. T. (1958). Ageing and human skill. London: Oxford University Press. 
Wexley, K. N. (1984). Personnel training. Annual Review of Psychology, 35, 519-551.

Willis, S. L. (1985). Toward an educational psychology of the older adult learner: Intellectual and cognitive bases. In J. E. Birren \& K. W. Schaie (Eds.), Handbook of the psychology of aging (pp. 818-847). New York: Van Nostrand Reinhold.
*Winkle, R. (1991). Effects of personality, age and gender on learning in leadership training. Unpublished master's thesis, Bowling Green State University, Bowling Green, Ohio.

*Zandri, E., \& Charness, N. (1989). Training older and younger adults to use software. Educational Gerontology, 15, 615-631.

\section{Appendix A}

\section{Scope of the Literature Review}

The databases used in the computer searches were ERIC (19821987; 1987-1994); PsycLIT (1983-1987; 1987-1995); Dissertation Abstracts (1985-1994); ABI/INFO (1971-1994).

\section{Key Words}

References of all materials obtained were searched for usable data.

$\begin{array}{ll}\text { Acquisition } & \text { Age and evaluation } \\ \text { Learning and work } & \text { Older employee } \\ \text { Age and training } & \text { Retraining } \\ \text { Age and retraining } & \text { Age and work } \\ \text { Age and intervention } & \text { Practice } \\ \text { Learning and individual differences } & \text { Older worker education } \\ \text { Age and skill } & \text { Education } \\ \text { Computer-individual } & \text { Work and training older adult } \\ \text { Job skills } & \text { Obsolescence } \\ \text { Age and ability training } & \text { Employment } \\ \text { Training effects and older workers } & \text { Adult learning } \\ \text { Age and learning } & \text { Adult education } \\ \text { Individual differences } & \text { Job development }\end{array}$
Elderly and training
Instruction
Apprenticeship Managerial training

Psychology abstracts from 1969 to 1983 were searched for the terms training, personnel training, and industrial training. Dissertation $A b$ stracts from 1985 to 1994 were searched for adult and continuing education, industrial education, psychology and education, vocational education, gerontology, and training. Social Science Citation Index from 1986 to 1992 was searched under the Permutation Subject Index and Reference Journals with key words such as age/training, training/age, and training/adult.

\section{Journals Pertaining to Age and Work}

All volumes of the following journals were searched. Aging and Work Training and Development Journal Training Industrial Gerontology

Journal of the American Society of Training Directors

\author{
Journal of Applied Psychology \\ Psychology and Aging \\ Journals of Gerontology \\ Experimental Aging Research
}

\section{Appendix B}

\section{Calculation of Effect Sizes}

Many effect sizes were calculated using programs provided in the meta-analysis software described by McDaniel (1986) given the necessary primary data as described below. These programs implement common formulas available in many texts (Hunter $\&$ Schmidt, 1990).

1. Correlation coefficients were calculated from:

a. the $t$ statistic and its associated degrees of freedom. If a $t$ statistic was reported as "less than 1.0" (nonsignificant), a value of 1.0 was used.

b. the $2 \times 2$ chi-square and number of observations.

c. the Pearson point-biserial correlation coefficient and sample sizes of the two groups.

d. Cohen's $d$ and sample size.

It also was possible to calculate correlation coefficients from other summary statistics.

e. $F$ test statistic and sample size. Because $t_{N-2}=F_{(1, N-2)}$ (Hays, 1988 ), the square root of the $F$ statistic can be used as a $t$ with $N-2$ degrees of freedom. If an $F$ statistic was reported as "less than $1.0^{\prime \prime}$ (nonsignificant), a value of 1.0 was used.

f. Proportion pass $(p)$ and proportion fail $(q)$ and sample sizes for two groups. A form of the Fisher test can be used to test for equal proportions (Kirk, 1990); pass and fail rates in our case.

$$
\mathrm{Z}=\frac{p_{1}-p_{2}}{p_{p d} q_{d} / n+p_{p d} q_{d} / n}
$$

Where $p$ and $p$ are sample estimators of the population proportions, $n_{1}$ and $n_{2}$ are the sample sizes, $p_{p d}\left[p_{d}=\left(n_{1} p+n_{2} p\right) /\left(n_{1}+\right.\right.$ $\left.\left.n_{2}\right)\right]$ and $q_{d}\left[q_{d}=\left(n_{1} q+n_{2} q\right) /\left(n_{1}+n_{2}\right)\right]$ are pooled estimators, and $q$ is equal to $1-p$. If any of the products $n_{1} p_{d}, n_{1} q_{d}, n_{2} p_{d}$, and $n_{2} q_{d}$ are between 5 and 10 , a continuity correction may be applied by subtracting $(1 / 2)\left(1 / n_{1}+1 / n_{2}\right)$ from the absolute value of the $Z$ numerator. This correction should be used when $n$ is small and a continuous normal distribution is used to estimate probabilities in a discrete distribution (Kirk, 1990).

For large degrees of freedom, the distribution of $t$ approaches the standard normal distribution (Hays, 1988). However, because we were interested in calculating an effect size, and not the significance of that effect size, we treated the $Z$ statistic as a $t$ statistic 
with $N-2$ degrees of freedom (D. D. Doverspike, personal communication, September, 1994).

g. Mann-Whitney $U$ statistic and sample size (Glass, McGaw, \& Smith, 1981).

$$
r=1-2 \mathrm{U} /\left(n_{1} n_{2}\right)
$$

Studies reporting more than one effect size for a specific outcome measure (e.g., three-test scores)

h. These effect sizes were averaged into one effect size using a Fisher $r$-to- $Z$ transformation (Hays, 1988). The original statistics were converted into $r$ if necessary. The $r s$ were then converted into $Z$ s using an $r$-to- $Z$ table. These $Z$ s were averaged and reconverted into a single correlation. This method was chosen because the original effect sizes were often based on outcome measures derived from different metrics.

2. $d$ effect sizes were calculated from:

a. means, variances, and sample sizes for two groups.

b. the $t$ statistic and its degrees of freedom.

c. the Pearson correlation coefficient and sample size.

It was also possible to derive effect sizes from other summary statistics.

d. Means, variances, and sample sizes for more than two groups. Rather than using the extreme end groups, we decided to main- tain the continuous nature of the data and include data points from all study participants where possible. For instance, in the case of more than two groups, we pooled groups using age 40 as a general cutoff with persons over age 40 considered older workers using:

$$
\begin{gathered}
\text { pooled mean }=\frac{n_{1} x+n_{2} x}{n_{1}+n_{2}} \\
\text { pooled variance }=\frac{\left(n_{1}-1\right) s^{2}+\left(n_{2}-1\right) s^{2}}{\left(n_{1}-1\right)+\left(n_{2}-1\right)}
\end{gathered}
$$

3. A base-rate correction (Hunter \& Schmidt, 1990) was employed to correct for attenuation resulting from the artificial dichotomization of a continuous age variable.

$$
r=\frac{r \sqrt{(.25 / p q)}}{\sqrt{\left[(\sqrt{.25 / p q})^{2}-1\right] r^{2}+1}}
$$

Where $p$ is the proportion in one group and $q$ is the proportion in the other group $(1-p)$. 


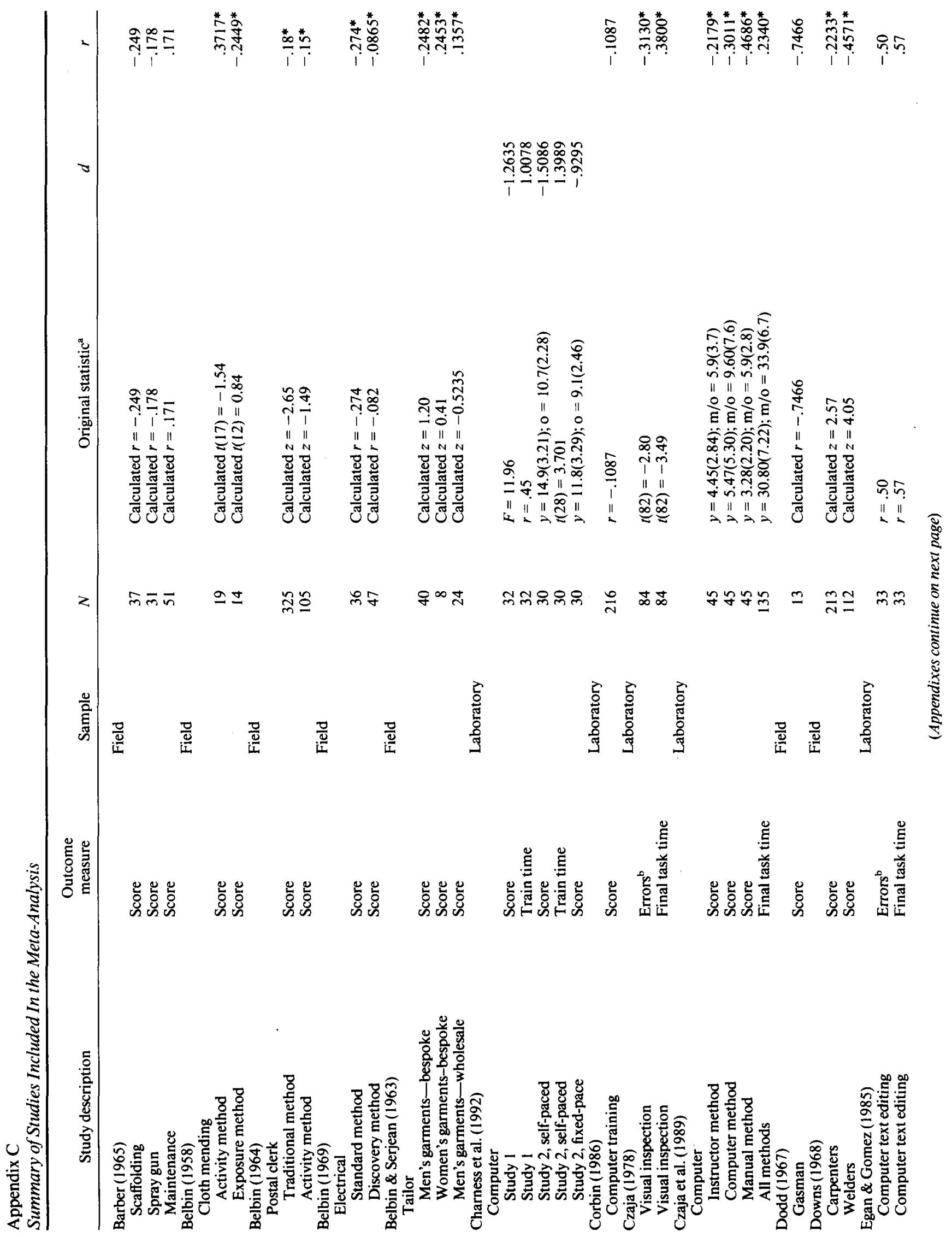




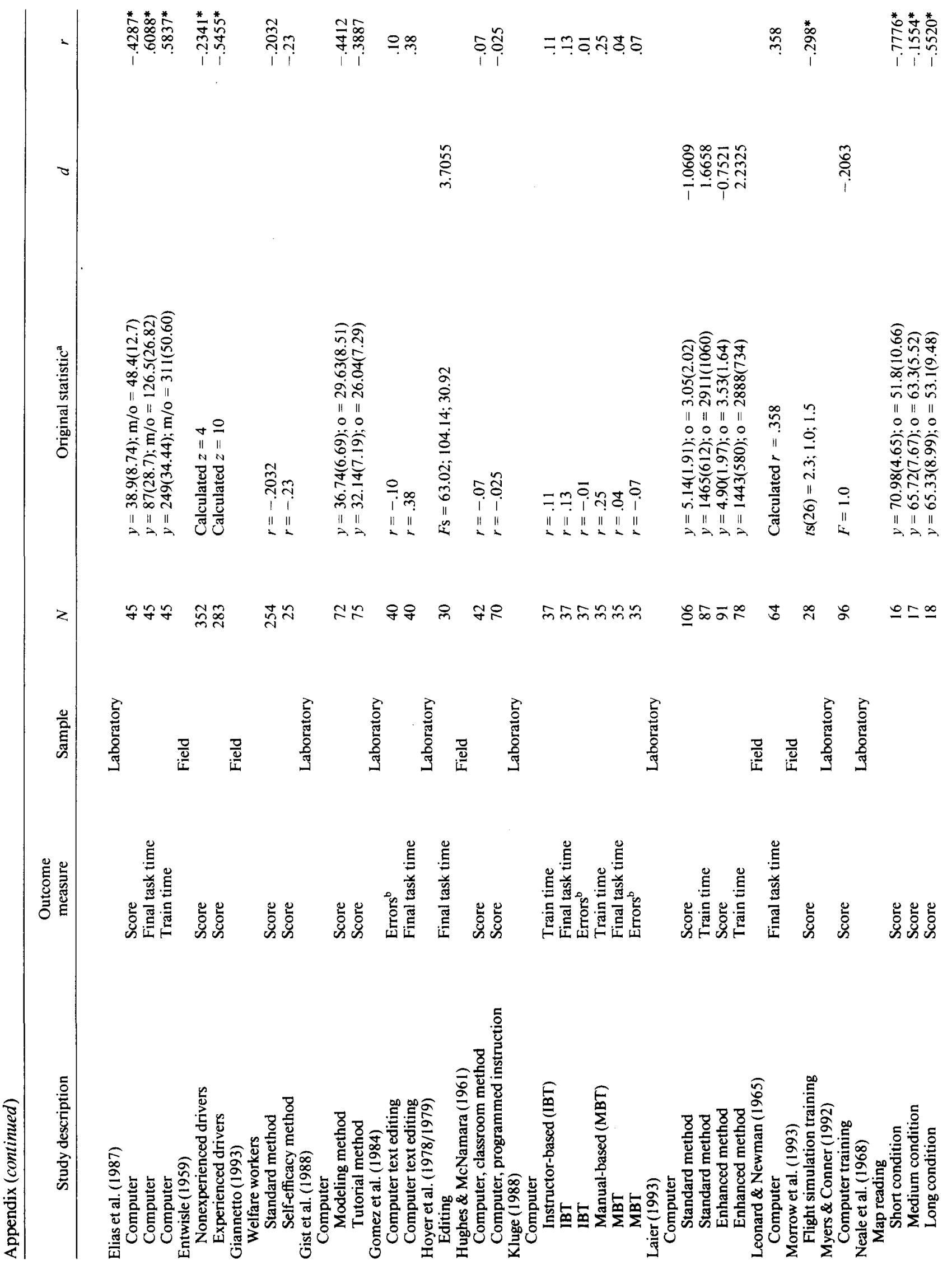




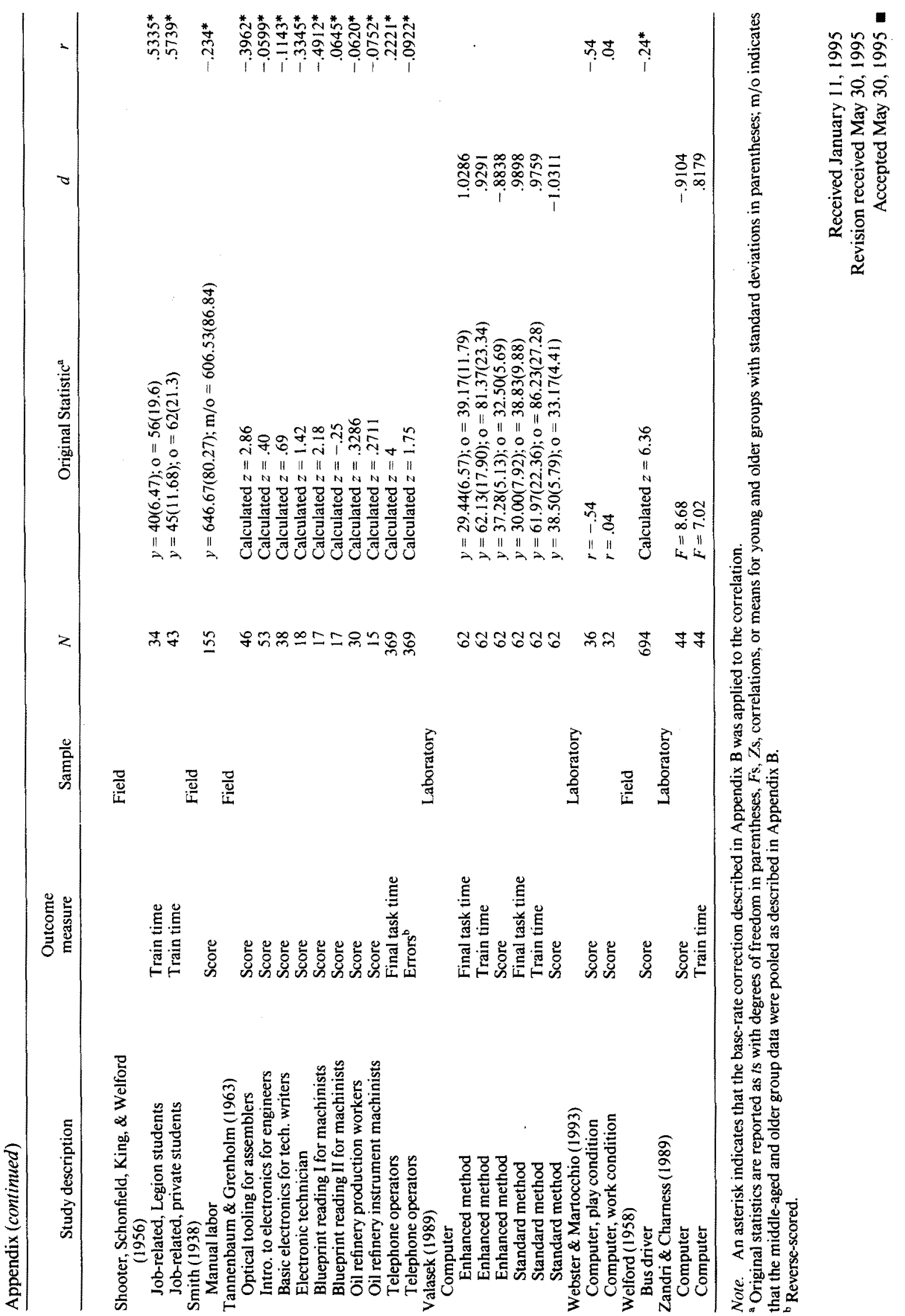

